\title{
LA ILUSION DE LAS ALTERNATIVAS: VIVIR EN PAREJA
}

\author{
FRANCISCO ORTEGA BEVIA \\ Director Master Terapia Familiar y Profesor Terapia Familiar, Curso Superior \\ Psicosociológico \\ Universidad de Sevilla
}

\section{ELISA PEREZ DE AYALA MORENOS SANTA MARIA}

Profesora Trabajo Social Familiar

Universidad de Sevilla

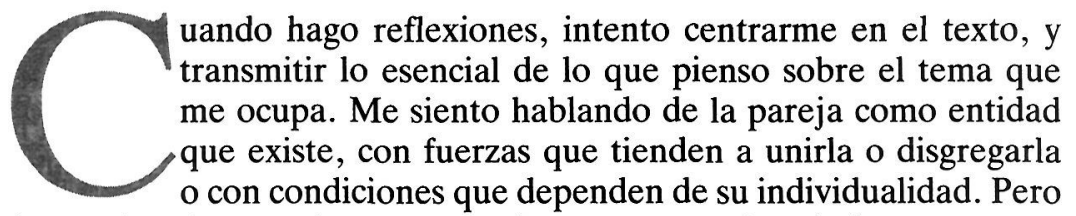
si atiendo a lo que pienso, me enfrento con muchas dudas.

La diferenciación es importante: ¿existe la pareja? Primera ilusión alternativa: La gente gasta mucha energía para realizar esa ilusión. ¿Cuánta gastan los adolescentes? En el mundo de los animales es el macho quien más energía gasta en el galanteo, por eso quizás la naturaleza le dota de los atributos físicos más llamativos.

Relación de pareja, se traduce en relación durable entre un hombre y una mujer, que genera hijos y que transmite la cadena generacional. De hecho, del acoplamiento que une dos cadenas y genera otra cadena. Genera una situación singular en la que se implican las peculiaridades de cada cual.

La familia es anterior a la pareja. Se cruzan líneas generacionales de arriba y abajo. La pareja es crisol, produce autonomía, sirve de ayuda frente a ciertas particularidades de la angustia y del sufrimiento (soledad, sentimiento de inferioridad, falta de seguridad, etc.). Le sirve al sujeto como colchón en su diferenciación y autonomía. También ayuda en determinados síntomas y ciertas dificultades en relación con los demás.

Pero también esto es ilusorio porque se concatena el propio rol con el padre. Se entra en relación con papeles de jerarquía e igualdad al mismo tiempo. Independizar e independizarse se dan a la vez. No obstante hay que llegar a asumir el papel de abuelo sin haber llegado a tener una relación de igualdad como pareja.

Entre la teoría Sistémica y la teoría de los ciclos de la vida hay un punto de unión, y es: la idea de que la mayor parte del tiempo se vive en pareja, pero funcionalmente, es la menor parte del tiempo la que 
se vive como pareja en la trayectoria hijo-padre-abuelo. Se va toda la energía en dar continuidad a la cadena. Nos estamos ocupando de los hijos cuando aún nos estamos casi separando de los padres... y se llega rápidamente a la vejez, a veces sin pareja.

La primera alternativa es: estarse preparando para la alternativa de elegir pareja y se nos difumina con las alternativas de otras funciones. Segunda ilusión de las alternativas.

Para unos autores, la pareja es una entidad fundamental, para otros no. Como especialista, no me preocupa la pareja desde su prisma artístico, o literario o teatral. Me preocupa por el sufrimiento que puede generar esa relación. Me interesa su desarrollo para conocer las razones que conducen al sufrimiento.

Consideramos poco que la pareja es una resultante contractual y no una pertenencia previa, como ocurre con la familia de origen. Este aspecto ha estado presente pero nos pasa desapercibido.

¿Los contratos matrimoniales existen? ¿Qué cabe decir sobre el contrato? ¿Que es otra ilusión? Es un hecho histórico, regulado socialmente, que ha ido variando a lo largo de los tiempos y que en la actualidad también es distinto del de la situación inicial.

Actualmente lo contractual es más personal y más individual. Inicialmente no había contrato escrito. Lo contractual lo regulaba el Derecho Romano. Se especificaban los bienes aportados al matrimonio. El Derecho Castellano del siglo XVII habla ya de contrato escrito.

Utilizando un término más castizo, podemos hablar de capitulaciones (nos da más pie a análisis). En ellas se habla de los términos en que se va a basar la relación entre dos. Sager señala el hecho de una capitulación en el 400 y pico a. de C. entre una judía conversa y un funcionario del templo de Alejandrina, en el que se ve el regateo del contrato entre uno y otro y cómo la inteligente judía carga en su favor las condiciones del pacto matrimonial.

El matrimonio como tal es uno de los contratos más importantes. La gente se prepara para vivir ese contrato. Sin embargo hasta 1960 sólo los TRABAJADORES SOCIALES asesoraban en este materia y sólo muy recientemente es estudiado por especialistas, pasando posteriormente a ser atendido en conjunto por los profesionales de orientación sistémica. Aun hoy, como dice Bergman, no existen estudios serios y concretos sobre las relaciones de pareja ni podemos disponer de un sistema teórico de diagnóstico preciso, ni recursos terapéuticos de efectividad comprobada. Olson también señala la falta de tronco teórico para entender el tema matrimonial.

Pero lo cierto es que esta importante Institución para la que las gentes, las familias se preparan y gastan tanta energía en preparar a sus miembros, resulta ser frágil e inestable.

Sólo en Estados Unidos, en 1975, hubo un millón de divorcios, lo que representa uno por cada dos matrimonios. Eso da idea de la ines- 
tabilidad y la dificultad de esta Institución. Pero también de su prestigio.

Desde el punto de vista de la economía relacional es catastrófico, como entidad social algo ocurre. Las capitulaciones eran antes más sociales y más estables. La gente no establece un verdadero contrato sino un conjunto de espectativas de deseos y de obligaciones que cada uno tiene respecto del otro y que nunca han sido explicitadas. Cada miembro de la pareja cree que recibirá del otro lo que esperaba a cambio de lo que él dará y que resume en la capitulación que nunca fue explicitada. Además la vida trae circunstancias, hijos, etc., que hacen que lo convenido tenga que reestructurarse constantemente, incluso que pueda ser cambiado por uno sin consentimiento o conocimiento del otro... la cosa se complica.

Desde el punto de vista clínico conviene señalar tres niveles en la capitulación matrimonial:

1. Puntos conscientes y expresados. Aquí nadie se engaña: «yo compraré el sofá y tú el comedor», «si me tratas dulcemente te daré cariño», etc.

2. Puntos conscientes y no expresados: «sólo te soportaré si tú no me instigas».

3. Los no conscientes: «Seré la preferida, ya que no lo fui en mi casa».

La debilidad de este contrato es evidente.

Los puntos del apartado uno llevan a la persona a la vicaría, los segundos comportan dificultades en la primera etapa del matrimonio, los terceros suponen elecciones patológicas de pareja.

Capitular es realizar un pacto entre dos personas sobre algún negocio importante para ambas. Pero también significa llegar a un acuerdo entre dos fuerzas beligerantes o enemigas para estipular las condiciones de rendición de una de ellas. Así pues, se «capitula» o se «capitula». Se capitula antes de empezar la relación matrimonial o como consecuencia de la misma (definición primera o definición segunda), pero siempre se capitula.

Tercera alternativa importante: se desliga uno o no se desliga para establecer una relación de pareja. La alternativa es antropológica y no voy a entrar en ella, pero si uno no se desliga no es posible jugar a nada en la intimidad. Y desligarse es desligarse también de los juegos de la propia ligazón familiar porque uno tiene que establecer nuevos juegos de relación.

Esto ha sido resuelto a lo largo de la historia de varias formas. No voy a entrar en esto pero sí voy a señalar una para matizar lo que quiero decir.

Como rito curioso, por ejemplo, el del rapto. Está en la mitología griega, en la romana, en el cine y en nuestra cultura. 
En el rapto hay una forma de alejar a la mujer del patronazgo de «sus dioses» para introducirla en el patronazgo de los dioses del esposo. Cambiemos dioses por reglas de relación y tendremos la traducción sistémica del ritual.

Cuarta ilisión alternativa: ¿cómo es esta historia desde la perspectiva sistémica? Los autores difieren en orientación y enfoque epistemológicos. Aunque todos estamos de acuerdo en la importancia de la pareja como entidad, para unos es entidad fundamental y para otros es consecuencia de la existencia de otra red de relaciones. Por tanto estamos en la duda de si es una existencia virtual o una parte de un todo más amplio. Para muchos, incluso la pareja no existe, es una tríada, ya que sólo se define en la medida que entendemos la inclusión o exclusión de una tercera persona, un otro u otra, persona en fin que tiene que ver con otras de niveles generacionales diferentes.

Para poder entender esto mejor, podemos sistematizarlo de otra manera y decir que unos entienden que la pareja es una instancia virtual, dentro de una red más amplia (eje diacrónico), a lo largo del tiempo, el suceder de la vida y el desarrollo de la naturaleza; y otros lo ven desde un eje sincrónico.

Entre los que lo ven desde un eje diacrónico están los de la escuela de Ackerman, Bergman, Hoffman, etc. La díada es aquí una parte integrada dentro de otros subagrupamientos sistémicos. Haley, por ejemplo, invita a la perspectiva del eje de la vida y sus intervenciones terapéuticas tendrán este sentido; son estrategias, intevienen en momentos críticos para restablecer la línea natural del ciclo de la vida.

Una intervención estratégica, intervención realizada para establecer las relaciones sexuales, por ejemplo: un paciente acude a la clínica porque recién contraído matrimonio, vuelve del viaje de bodas con una importante pérdida de peso; otro viene por la misma razón (la pérdida es de más de 10 kilos). Los dos son ingenieros. En ambos casos están viviendo una presión social importante (compañeros de trabajo que hacen chistes, etc.) El primero está muy angustiado porque después de casi dos meses no ha podido consumar el matrimonio y en el segundo, la situación es muy diferente porque el sujeto está acomplejado porque la demanda sexual de su pareja es superior a lo que él le puede dar.

El primero tuvo muchas relaciones sexuales antes del matrimonio y muy satisfactorias. El segundo no había tenido ninguna experiencia previa pero manifiesta que más de 7 veces al día no puede mantener relaciones sexuales. Estamos ante dos formas diferentes de fracaso.

Una intervención estratégica aquí sería dejar las cosas en su lugar, ni tanto ni tan poco. Retomar la condición natural de la relación sexual dentro de la relación de pareja, de forma que se pudiera realizar convenientemente y no ligada a otras que no tuvieran que ver. Esto corresponde al eje diacrónico. 
En ambos casos se ha debido producir el desligamiento y en ambos casos no se ha producido. Las circunstancias del sujeto son distintas pero el sufrimiento es el mismo. No existe pareja en ninguno de los dos casos porque no se han desligado y diferenciado.

Uno puede no desligarse y establecer una relación de continuidad con una pareja, desligándose de forma subrepticia y volviéndose a ligar a continuación. Por ejemplo: la chica que se queda embarazada para desligarse de su familia de origen pero se religa inmediatamente con la madre a través de la nieta. La cadena generacional sigue, aunque ella esté ahí, como metida en un paréntesis. Y nuevamente la ilusión de las alternativas, en este caso de distanciamiento.

Minuchin es sujeto apropiado para atender si las escuelas estructurales creen en la existencia de la pareja. En su enfoque hay un planteamiento singular pues, para él, la pareja es un subsistema dentro de un sistema mayor, donde existe un problema de límites, de fronteras, pero no está desligado. El subsistema, para mantenerse, exige un esfuerzo constante en el sostenimiento de sus fronteras, pues se ve permanentemente amenazado.

Framo y todos los que tienen que ver con los que entienden la pareja ligada diacrónicamente en relación con las expectativas, están vinculadas con los planteamientos acerca de la patología.

Whitaker no entiende la pareja no ligada al origen de los cónyuges y no comienza una terapia mientras no vea todos los miembros. Otros autores no consideran esto indispensable; Watzlawick, por ejemplo, funciona a nivel del eje sincrónico. Las reglas que rigen el subsistema conyugal están vinculadas con las que mantienen el resto de las relaciones familiares. Y en Watzlawick hay algo importantísimo que es la dependencia-sumisión y la competencia cuyas reglas tanta importancia tienen en las disfunciones conyugales.

$\mathrm{Ni}$ siquiera todos los terapeutas familiares que trabajan asiduamente lo hacen con la idea de que la pareja es independiente, sino como una relación triangular. Un problema cualquiera que se plantee es definido como conyugal, con lo que queda configurado con la relación de padre, etc. Volvemos al enfoque de la pareja como subsistema, ligado a otros subsistemas dentro de una globalidad.

En muchos casos, la indicación de una terapia de pareja, cuando aparece un hijo sintomático (por ejemplo, un chico con cuadro de tics, terrores nocturnos, etc.) se establece cuando los síntomas que presenta el hijo ya no tiene más necesidad de tratamiento. De manera que sólo nos ocupamos de lo que suponemos que es importante y andamos despistados en lo que nos parece que es secundario.

Como plantea Bowen, todo esto de los conflictos se vuelve triangular. Las triangulaciones, necesariamente son hacia arriba o hacia abajo. Si uno se ha quedado ligado en la familia de origen y tiene un hijo, está ligado hacia arriba, y si se liga a un hijo en su conflicto de 
pareja, está ligado hacia abajo; pero en los dos casos está triangulado.

La triangulación es un elemento constante en los problemas de pareja.

Los triángulos son normales en la vida de las personas, pues éstas se juntan o se distancian para cooperar con alguien o contra alguien en la vida social y familiar. Pero nosotros nos preocupamos por los que tienen que ver con patología, sufrimiento o mal funcionamiento. El triángulo perverso, por ejemplo, es una forma de salir del conflicto de pareja y es una realidad que tiene que ver con las estructuras sociales.

Quinta ilusión: Sólo el amor es eterno. Para introducir este tema, tendría que decir que no sólo hay uqe considerar las dos personas, sino la naturaleza del vínculo. Tiger y Fox realizaron un trabajo de psicología comparada con primates. Ellos acaban describiendo dos tipos de vínculos con las personas. Dicen que los animales tienen un tipo de vínculo pasajero y otro estable y que no se puede pasar directamente al estable sin estar en el pasajero pero sí del estable al pasajero.

Las jerarquías animales, en las que el celo se ciñe a ciclos temporales, nos llevarán a entender esto más claramente. Una perdiz se interesa por otra perdiz de forma pasajera. Cumple con la función de procreación y al año siguiente tendrá otra. En las colonias de primates esto no es así porque se continúa con una organización social.

El vínculo a corto plazo es un control que ejerce el macho sobre las hembras, lo ejerce el macho con fines sexuales y de dominio y las hembras lo utilizan para controlar su fecundación. De manera que participan en esto juegos para protegerse y procrear, mientras que el macho lo hace con intereses sexuales y de dominio. Este vínculo es efímero y tiene una duración breve.

El otro vínculo es el de largo plazo. Este no tiene una justificación sexual. En realidad es un vínculo de protección de la prole. Es un rol duradero que incluye a la hembra y a la descendencia. El vínculo pasajero es determinativo y biológico, el segundo es de las condiciones de vida, es social.

La sociedad impone al varón el vínculo de largo plazo; de lo contrario, la situación sería de juego a vínculos de corto plazo permanentemente, si no asume la responsabilidad de la continuidad de la tarea.

El vínculo de corto plazo se caracteriza por la intensidad de los sentimientos sexuales y amorosos pero también por la angustia de pérdida, de manera que el vínculo de corto plazo, en la raza humana, tiene de 3 meses a 3 años de duración y más allá de eso sólo se permanece en pareja en relación con el vínculo de largo plazo.

El vínculo de largo plazo produce una profunda aceptación del compañero y una aceptación de las limitaciones que tiene esa situación. Implica la decisión de ambos de compartir y atravesar juntos ciclos de la vida, implica cuestiones como fidelidad, dedicación y participación en la intimidad. Cuando la relación es agradable, se mantiene así pero 
cuando es desagradable, el vínculo de largo plazo implica el mantenimiento a expensa de la inversión de elementos afectivos, de la hostilidad, ira, angustia, miedo, etc., y entonces... o se capitula o se capitula. O se capitula y se acepta la situación o se capitula la rendición del enemigo.

El vínculo de corto plazo funciona para la hembra y el varón aunque más para el varón. El macho funciona a corto plazo y no se implica, no se queda embarazado, la hembra sí y con ello se implica e implica al varón. Consecuentemente la sociedad implica al varón en el vínculo de largo plazo y la mujer, para hacérselo más agradable, se esfuerza en recapturar su excitación, en mantener el aura de los primeros momentos del amor, a veces infructuosamente.

De manera que volvemos al punto de partida. Está tan comprometida la pareja como figura relacional que la posibilidad que tiene una pareja de funcionar correctamente es bajísima porque está terriblemente amenazada por las líneas generacionales que vienen de arriba, de las que vienen de abajo, de la presión social, de sus propias dificultades, de las capitulaciones mal hechas, de los cambios a los que hay que adaptarse, etc., y sólo es posible mantener una relación así en el contexto de un grado de diferenciación elevado. Sólo las personas que tienen un grado suficiente de diferenciación son capaces de mantener sin disolución los límites de la relación. Sólo en estas condiciones existe la alternativa real: vivir en pareja. Los demás están decididamente obligados a capitular o a triangularse o a coaligarse. 